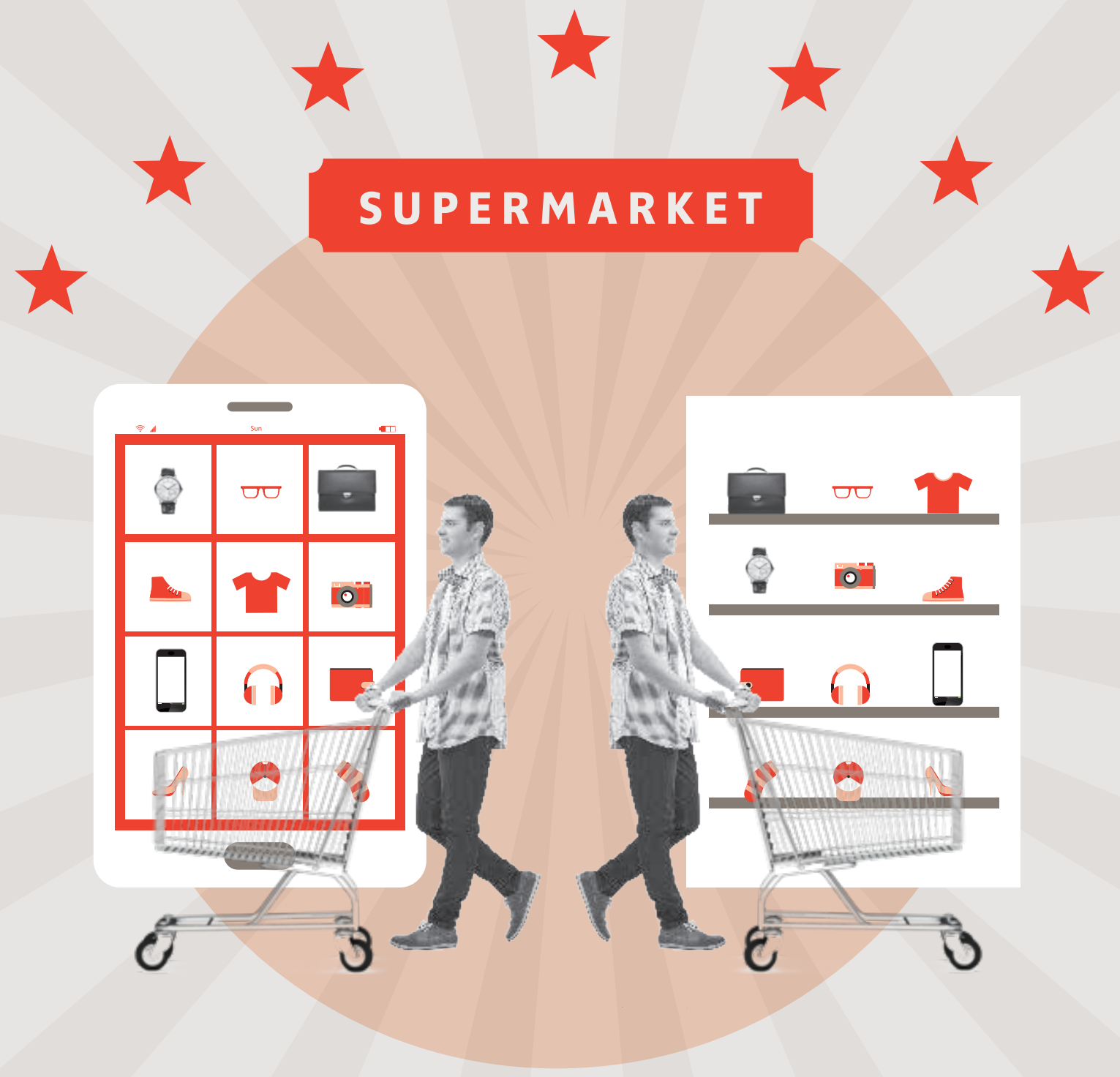




\title{
E-Commerce in a Physical Store: Which Retailing Technologies Add Real Value?
}

\author{
Peter Linzbach, J. Jeffrey Inman and Hristina Nikolova
}

KEYWORDS

Instore E-commerce, Retail Technology, Marketing Automation, Process Automation, Customer Response

THE AUTHORS

Peter Linzbach

Chairman \& CEO, Small Capital Investment $\mathrm{GmbH}$ and Visiting Lecturer, University of Cologne,

Cologne, Germany peter.linzbach@uni-koeln.de

J. Jeffrey Inman

Albert Wesley Frey Professor of Marketing, Katz Graduate School of Business

University of Pittsburgh, PA, USA jinman@katz.pitt.edu

Hristina Nikolova

Coughlin Sesquicentennial Assistant Professor of Marketing, Carroll School of Management, Boston College, Boston, MA, USA hristina.nikolova@bc.edu
Hard times for physical stores /// The progress in digitalization is playing hard on many traditional retailers. The growing share of e-commerce is leading to an erosion of customer loyalty and an ongoing drop in footfall and revenues in physical stores. Consumers follow a different path in making and carrying out their shopping decisions and online retailers are taking their share. They are able to offer alternative and attractive value propositions with wide and deep assortments, convenient shopping processes and personalized and customized solutions. Instead of presenting an "average" offer to an "average" target group they have consumer access in the moment of decision taking. Even within a physical store environment, customers can go online anytime and visit an online retailer's site. To remain competitive, offline retailers have responded with integrating digital in-store technologies into their physical servicescapes. Often, the introduction of multichannel connecting services like click \& collect or order from or return to store are first steps. Nowadays, upgraded technology solutions allow a cohesive shopping experience and can leverage both the benefits of e-commerce and inperson, physical store shopping. The overall attempt of brickand-mortar retailers is to digitally engage physical shoppers on their journey with a personalized shopping experience, thus creating a kind of 4.0 multichannel experience. The range and number of available shopper-facing technologies is growing constantly but they are not yet widely implemented. But do shoppers respond positively and does the investment pay off for retailers?

Shopper-facing technologies /// Bundles of hardware and software are developed to change or enhance the interface between retailers and customers within the physical retail setting. Retailers are faced with dizzying options of technologies that require a multitude of IoT devices and related connectivity solutions (see Figure 1 for an overview). 
FIGURE 1:

\section{Shopper-Facing Retail Technologies}

MARKETING TOOLS

To

E N A B L I N G

Customer identification

Data Collection

Data Analysis

$\rightarrow$ Geo-tracking/-fencing

$\rightarrow$ Beacon technologies

$\rightarrow$ Cameras

\section{EXECUTING}

Customized promotion Customized information Proximity Marketing

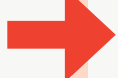

$\rightarrow$ Complementary products

$\rightarrow$ Recommendations

$\rightarrow$ Price offers

$\rightarrow$ Loyalty program

$\rightarrow$ Incentives

PROCESS AUTOMATION TOOLS

\section{BACK END}

Merchandising \&

Replenishment

$\rightarrow$ Smart shelves

$\rightarrow$ Digital price tags

$\rightarrow$ Robotic replenishment

\section{FRONT END}

Scanning \& Payment

$\rightarrow$ Automatic queue management

$\rightarrow$ Self/automated scanning

$\rightarrow$ Cashier-less checkouts

$\rightarrow$ Mobile payment

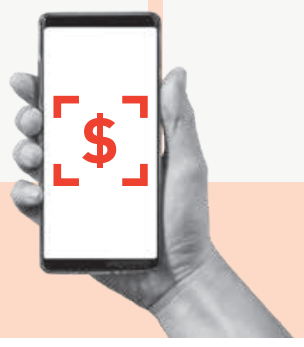

> Marketing tools /// collect data as soon as the customer comes near a retailer. Geo-tracking/-fencing and Bluetooth- or WiFi-based beacon technologies support identifying a person's current location, navigation and activities via smartphone. Also, customers who already have a relation to a retailer can actively identify themselves, e.g. at self-service terminals. Additionally, cameras with biometric face recognition capabilities monitor the shop floor and can identify the customer's gender, age or height, and their sentiment, gestures or speech. Predictive analytics, data mining plus artificial intelligence may then generate insights to create and transmit in-store personalized and customized offers. Corporate or third-party mobile applications on consumers' smartphones may provide content of interest, like complementary products or recommendations, or offer price incentives like coupons, discounts or free samples to consumers identified as existing or loyal customers. All data may be enriched by further information or research features, for example, by visual search, and is ideally linked to information about previous consumer behavior both online and off-line. Additionally, smart in-store installed communication devices support mobile devices in making the physical customer journey more customized. These socalled proximity marketing tools operate either one-way and semi-targeted, such as with normal screens, video monitors or intelligent shopping carts, or two-way and responsively, like with digital screens, smart mirrors or AR/ VR-centers for virtual simulations of product interactions.

$\gg$

\section{Upgraded technology solutions} allow a cohesive shopping experience and can leverage both the benefits of e-commerce and in-person, physical store shopping. 
$>$ Process automation tools /// are merchandise-handling technologies that help retailers improve their cost efficiency and to ease customers' shopping journeys. Those tools automate back-end work processes like merchandising or replenishment or offload work to customers, e.g. for check-out and payment.

Shopper-facing technologies /// are merchandisehandling technologies that help retailers improve their cost efficiency and to ease customers' shopping journeys. Those tools automate backend work processes like merchandising or replenishment or offload work to customers, e.g. for checkout and payment.

\section{Shoppers and in-store technologies /// Consumer} response depends on availability, awareness and perceived attractiveness of solutions. Traditional, widely implemented and communicated multichannel services like click-and-collect are well known and utilized by consumers. Modern shopper-facing technologies like mobile payment are well known, but hardly available; others are currently not known, available or utilized, like store navigation or augmented reality offers (see Figure 2). Due to rare store implementation levels, the evaluation of the attractiveness of such technologies is still difficult. In general, the technologies can improve offers or shopping convenience through customization and enable a more emotional shopping experience. On the other hand, they are partly designed to operate silently and invisibly in the background and require customer activities such as signingin, downloading or learning applications, or changes in handling processes or additional tasks, like scanning. As a result, they might highlight the dark side of new technologies: One person may regard in-store technology as helpful and convenient, another might see it as a challenge to the shopper's technological skills or as a purposeful degradation in service quality. One may regard data transparency as an entry to better offers, another may raise serious privacy concerns. In a physical store environment and in high-density-areas such as indoor and outdoor shopping centers, customers might feel swamped with messages. Negative perceptions may cause on-spot refusals, potentially followed by lower future retailer patronage intentions or negative word-of-mouth. These potential downsides might attenuate or even reverse the monetary benefit.

How to evaluate new retailing technologies /// Adoption decisions of shopper-facing technology should be expanded beyond what the technology can potentially

FIGURE 2:

Awareness und utilization of selected digital retail services

THE FOLLOWING RETAIL SERVICES TO CUSTOMERS ARE ...
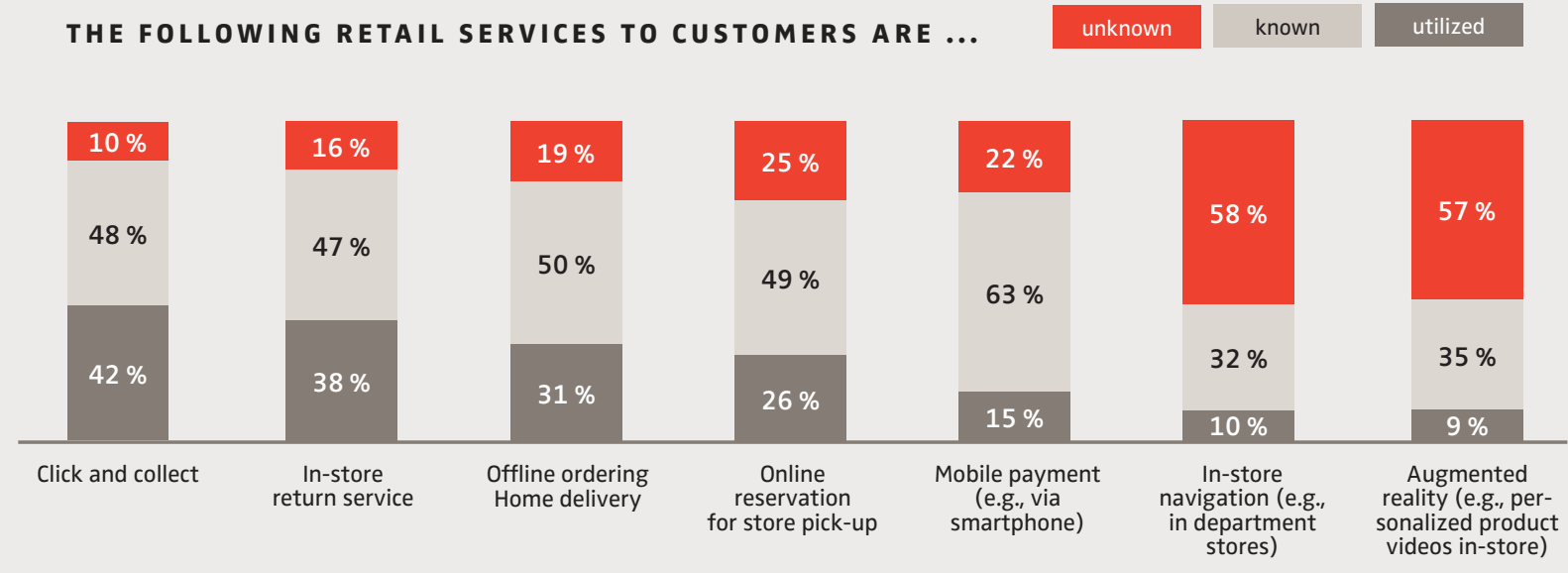

from: Representative study conducted in Germany 2018 ( $n=1500)$; published by EY Parthenon 
FIGURE 3:

\section{The impact of retail technology on shopper perceptions} and reactions and retailer profit changes

\section{RETAIL TECHNOLOGY}

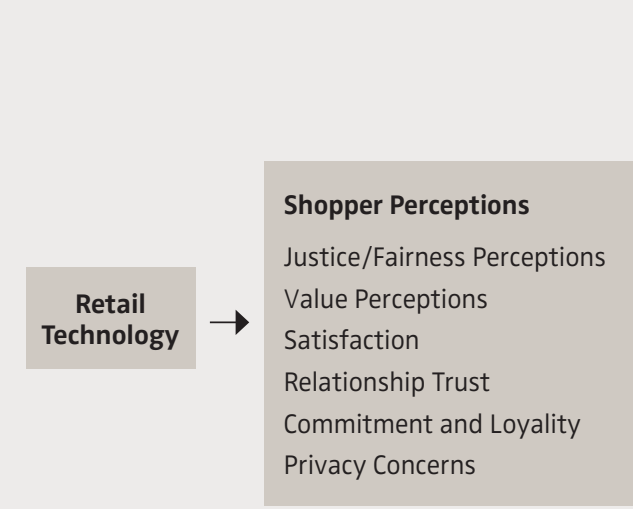

(for details on the study, see Inman/Nikolova, 2017)

\section{IMPACT ON SHOPPERS}

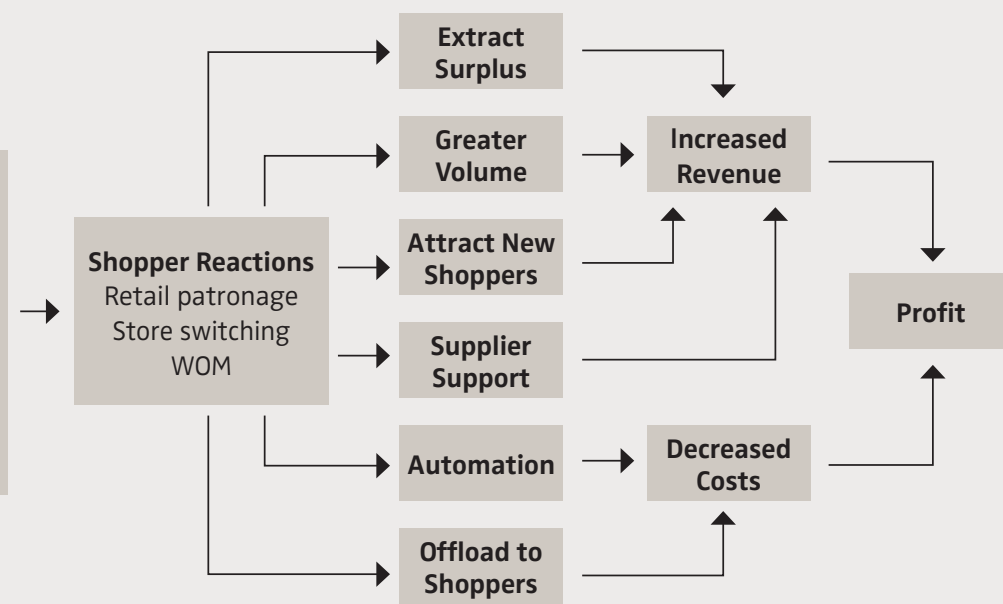

deliver to consider what the technology will deliver from a shopper's perspective. A framework developed by Inman and Nikolova gives some guidance on which aspects should be considered on the retailer and the consumer side (see Figure 3). Shoppers assess the fairness of the exchange with regard to procedures, outcome and treatment and the value of the technology they receive compared to what the retailer gets. Also, satisfaction, trust and privacy concerns are relevant to a customer's evaluation of technology. In a study of six different retailing technologies, marketing as well as process automation tools at local grocery stores were analyzed to test how customer perceptions were affected, leading to attitudinal and behavioral reactions. The study revealed the following effects.

> In general, the retailing technologies were considered useful and easy to use, and shoppers indicated that they would likely use them. The only exception was proximity marketing, which produces mixed reactions.

$>$ Retail technologies have significant effects on future retailer patronage intentions and on the shoppers' willingness to share positive word-of-mouth about the retailer.
$>$ Respondents reacted rather negatively on proximity marketing activities or smart shelves. Shoppers had serious reservations about proximity marketing and they questioned fairness and doubted consumer value. On top of that, they stated privacy concerns.

$>$ Automatic queue management was perceived positively and did not raise privacy concerns. As this technology is "invisible" to the customers - as other process automation tools might also be - retailers should make shoppers aware of these technologies and their benefits to foster positive word-of-mouth.

$>$ Visible process automation technologies like self-checkout, scan and go and mobile apps as a marketing tool were perceived slightly positively and less critically in terms of privacy.

Critical success drivers for implementing retailing technology /// Shopper-facing advanced technologies can be key to creating a different physical shopping experience for consumers and delivering benefits to retailers such as improved traffic, conversion and baskets or streamlined operational cost. These benefits can only be realized if cus- 
tomers engage with the technologies. To encourage engagement, retailers need to consider some critical success drivers of retailing technology.

$>$ Ensure functionality and safety /// Functionality is related to the complexity and technological lifecycle of the respective technology. Some functions are well developed and safe, such as mobile apps or digital signage, others, often more complex ones, are at an early or experimental stage and not yet fully reliable (such as beacon, cashierless checkout or mobile payment technologies). For example, Amazon's unattended "Just Go" solution has to handle high complexities and has only been implemented in one single store so far. All handling tools require $100 \%$ functionality, as failures or defectiveness would cause inefficiency or financial damages (such as non-cashed articles) and would discourage customers.

$>$ Evaluate investments realistically /// The question is to what extent and in what time technology investments can generate monetary benefits. It is important for retailers to evaluate input like content production cost, operating cost and one-time investments against output like revenues, gross margins and cost reductions. The cost and output of process automation tools are traceable and predictable on a store level, while the cause-effect relation of customer information and marketing tools is more difficult to predict and trace. The latter demands comprehensive data collection and analysis and ideally the set-up of feasible control groups. Results may vary by different products or target groups and store formats. As an example, store navigation, product locators and smart shelve technology tools are a value-add in large scale boxes like Hypermarkets or DIY stores, but much less efficient in smaller specialty stores.

> Manage customer concerns actively /// While most of the technologies were perceived well, proximity marketing seemed to trouble consumers. To encourage adoption, retailers need to convince customers that activities like in- and out-of-store customer tracking generate significant value for shoppers. Retailers need to address privacy concerns and build trust, if they want proximity marketing to deliver on its promise of increasing basket size or attracting new shoppers.

How should retailers move ahead now? /// They must strike a balance between old school retail and cutting-edge technology, ask their customers what they want, thoroughly

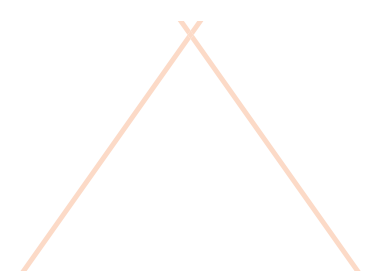

analyze and evaluate all technologies, manage concerns and not chase everything shiny that competitors might be trying out. Uncertainty, investment level and complexity suggest a test-and-learn culture and step-by-step approach with store piloting and (ideally) funding by suppliers. As consumer response is core, open and transparent promotion and easy to understand communication for applications is indispensable. Online and offline will merge to ensure a totally seamless and frictionless, truly two-way, interactive customer journey. By 2020, $30 \%$ of all human interactions will be with smart devices, and retailers must build respective capabilities, both for the management of content and the management of devices. So, on a long-term perspective, applications that would be called "nice-to-have" and are far away from paying off, might still be a worthwhile investment.

l.

\section{FURTHER READING}

Inman, J. Jeffrey; Nikolova, Hristina (2017):

"Shopper-Facing Retail Technology: A Retailer

Adoption Decision Framework Incorporating Shopper Attitudes and Privacy Concerns," Journal of Retailing, Vol. 93 (1), 7-28.

Inman, J. Jeffrey; Nikolova, Hristina (2017):

"Shopper-Facing Retail Technology: A Retailer

Adoption Decision Framework Incorporating Shopper Attitudes and Privacy Concerns," Journal of Retailing, Vol. 93 (1), 7-28.

Willems, K.; Smolders, A.; Brengmann, M.; et al. (2017):

"The path-to-purchase is paved with digital opportunities: An inventory of shopper-oriented retail technologies.", Technological Forecast and Social Change, Vol. 124, 228-242.

Betzing, Jan H.; Hoang, Anh-Quoc Martin and Becker, Jörg:

"In-store Technologies in the Retail Servicescape", http://mkwi2018.leuphana.de/wp-content/uploads/MKWI_3.pdf 